\title{
Closed anterolateral total talar dislocation: a case report and technical notes
}

This article was published in the following Dove Press journal:

Orthopedic Research and Reviews

22 April 2014

Number of times this article has been viewed

\author{
Yousef A Alrashidi' \\ Zubair A Wali \\ Khalid I Khoshhal' \\ 'Department of Orthopedic Surgery, \\ College of Medicine, Taibah University, \\ 2Department of Orthopedic Surgery, \\ King Fahd Hospital, Almadinah \\ Almunawwarah, Saudi Arabia
}

Background: Standard treatment of closed total talar dislocations (TTDs) is a controversial issue due to the rarity of the injury.

Case presentation: We report a case of closed anterolateral TTD in a 30-year-old male treated successfully by a closed reduction technique with no radiological evidence of avascular necrosis on 1 year follow-up.

Conclusion: Closed reduction has become the preferred modality of management of closed anterolateral TTD. This case supports, as found in recent literature, that closed reduction if possible in similar cases may yield a better outcome, although there is a need for high-level studies to prove the superiority of such a modality.

Keywords: closed reduction, closed talar dislocation, complete talar dislocation, pantalar dislocation, talus, total talar dislocation

\section{Introduction}

The talus is the most mobile tarsal bone that has no muscular or tendinous connections, with more than half of its surface lined with articular cartilage. ${ }^{1}$ The unique position of the talus in between the foot and ankle, in addition to its function in transferring force load means that major talar injuries and their sequelae may lead to significant disability. ${ }^{2,3}$

Talar dislocations can be "subtalar dislocations" or "total talar dislocations" (TTDs). Subtalar dislocations involve the articulation of the talus with the calcaneal and navicular bones. ${ }^{4}$ However, TTD involves the tibial articulation in addition to the calcaneal and navicular articulations. ${ }^{5}$ TTD can be anterolateral (commonest), medial, or posterior according to the displacement of the talus. ${ }^{1}$ Lietner described lateral and medial TTDs as sequelae of either forceful supination or pronation, respectively. ${ }^{6}$ On the other hand, Pinzur and Meyer ${ }^{7}$ described a pure posterior TTD as a result of forceful dorsiflexion associated with posterior thrust to the foot.

TTDs are rare injuries worldwide. ${ }^{8}$ Their prevalence is approximately $3.4 \%$ among major talar injuries depending on a few case series and reports in the literature. ${ }^{1}$

TTD can be associated with fractures involving the talus, ${ }^{5,8}$ malleoli, ${ }^{9-11}$ distal tibia, ${ }^{12}$ or fifth metatarsal, ${ }^{13}$ and it can be associated with navicular dislocation. ${ }^{14}$ It occurs commonly as an open injury with or without talar extrusion ${ }^{5,12,13,15-17}$ and less commonly as a closed injury. ${ }^{10,11,18-24}$

The treatment methods of open TTDs are variable in the literature; in addition to the necessary debridement of open wounds and fixation of associated fractures, they vary from closed ${ }^{1}$ or open reduction, ${ }^{22,23}$ to talectomy with tibiocalcaneal arthrodesis. ${ }^{5,25}$ 
Treatment of closed TTDs is controversial. In the past, many authors recommended open reduction. ${ }^{3,23}$ Recently, closed reduction has become more and more the treatment of choice. ${ }^{1}$ Although Mitchell was the first to partly describe a closed reduction technique in $1936,{ }^{24}$ no clear guidelines can be found in the literature. ${ }^{18}$

In the present report, the authors describe a case of anterolateral closed TTD associated with fourth metatarsal fracture treated successfully by a closed reduction. The technique of closed reduction is described thoroughly.

\section{Case report}

A 30-year-old otherwise healthy man was brought to the emergency room (ER) with a history of a fall in a construction hole of $3 \mathrm{~m}$ depth. He had an axial load injury to the right ankle and a twisting injury to the left ankle. He presented with severe pain and swelling of both feet but more on the left. The left foot was deformed, with marked prominence anterior to the lateral malleolus. The skin was tight over the prominence, with signs of skin compromise. Distal pulses were not palpable and capillary refill was slightly delayed. Neurological examination was normal. Plain anteroposterior
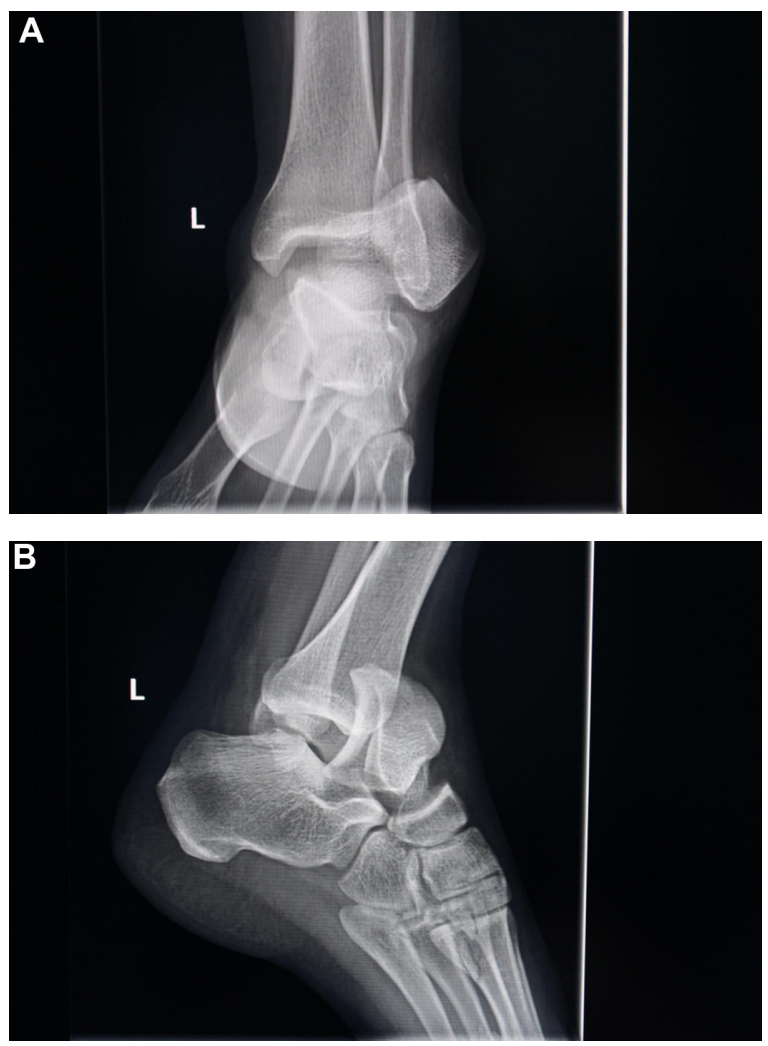

Figure I Plain anteroposterior (A) and lateral (B) radiographs of the left ankle at presentation revealed anterolateral total talar dislocation with rotational element associated with fourth metatarsal base fracture. and lateral radiographs of his left ankle (Figure 1) revealed anterolateral TTD associated with fourth metatarsal base fracture. There was a closed displaced calcaneal fracture in the right foot that was treated operatively 10 days later.

The advanced trauma life support (ATLS) protocol was applied. No life-threatening conditions were detected. A thorough secondary survey revealed no other injuries. Trial of closed reduction of the dislocation in ER by an orthopedic on-call resident under sedation was unsuccessful. It was in the form of foot longitudinal traction, leg counter traction, and backward pressure on the talus with the knee joint in slight flexion. Back slab was applied and the patient was prepared for surgical intervention. Within 5 hours of the injury, the patient was taken to the operating room after obtaining an informed consent for closed and possible open reduction.

Under general anesthesia, a closed reduction was attempted. Reduction was successful. Postreduction, no clinical or radiological instability was observed. The range of motion was full. Distal pulses and capillary refill improved after reduction. Back slab was applied. Postreduction radiographs showed restoration of the triple articulations (Figure 2). Computed tomography (CT) scans did not show any intra-articular fragment or osteochondral fracture.
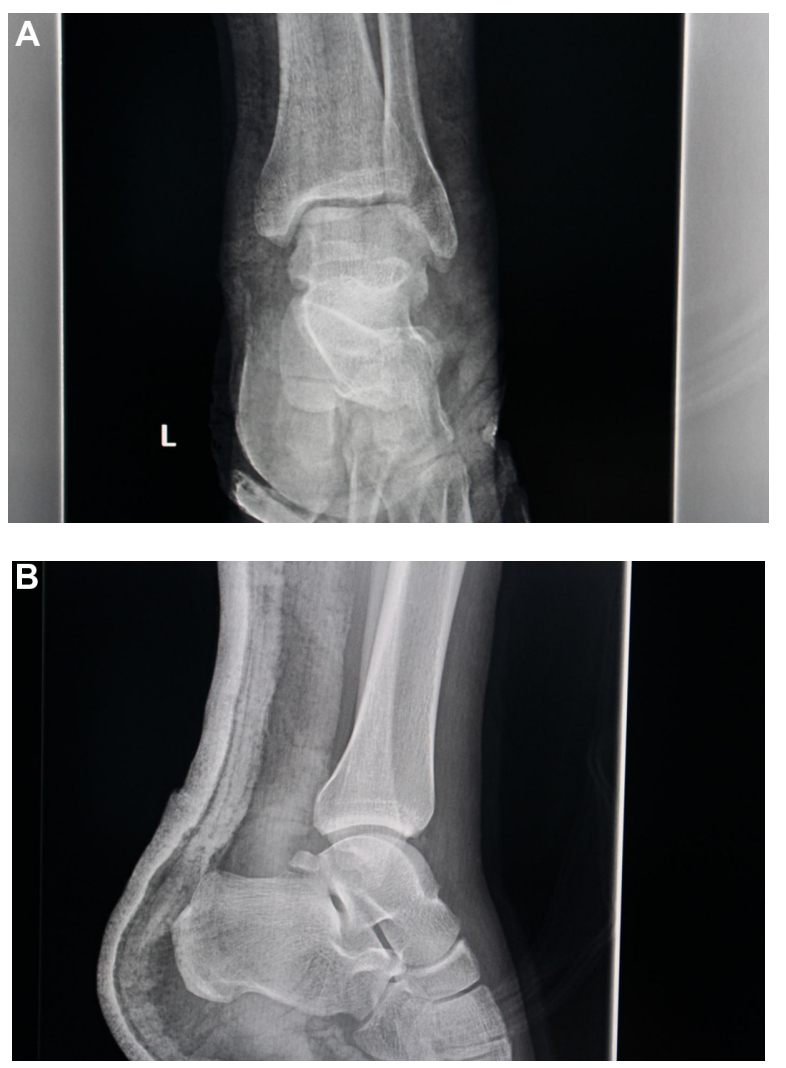

Figure 2 Postreduction anteroposterior $(\mathbf{A})$ and lateral (B) radiographs show restoration of the talar articulations with tibia, calcaneus, and navicular bones. 
Postoperative management included elevation, ice packs, and analgesia. Active range of motion exercises were started as pain and swelling subsided with time. The patient was mobilized in a wheelchair when the swelling subsided.

As the plain anteroposterior radiograph of the ankle showed medial malleolus hypoplasia, measurement of Elise ratio on the plain anteroposterior radiograph was made by dividing the medial malleolus length by the lateral malleolus length (normal values fall between 0.58 and 0.62 ). In the case in hand, it measured 0.5 , which suggests moderate hypoplasia of the medial malleolus (Figure 3). Medial malleolus hypoplasia is considered an important anatomic finding that may explain the susceptibility to dislocations around the ankle joint. ${ }^{26}$

Eight weeks later, the patient was sent for physiotherapy to start full weight-bearing on the left side and partial weightbearing on the right side. After 3 months, the patient was seen in the clinic and was found to have persistent left foot and ankle pain. Examination revealed that there was generalized tenderness and swelling and the skin was shiny. Magnetic resonance imaging (MRI) was performed to rule out avascular necrosis (AVN). MRI images (Figures 4 and 5) showed changes consistent with Sudeck's sympathetic dystrophy, but no signs of AVN. The patient was treated for Sudeck's sympathetic dystrophy with analgesia and physiotherapy protocol. Plain radiographs of the sixth month of follow-up showed talar subchondral lucency (Hawkin's sign) that indicates preserved talar vascularity (Figure 6). After 1 year, the patient is asymptomatic and had no signs of tibialis posterior dysfunction but there was a slight restriction in the range of motion (Figure 7). Also, the patient was seen at an 18-month follow-up visit with no significant clinical changes observed.

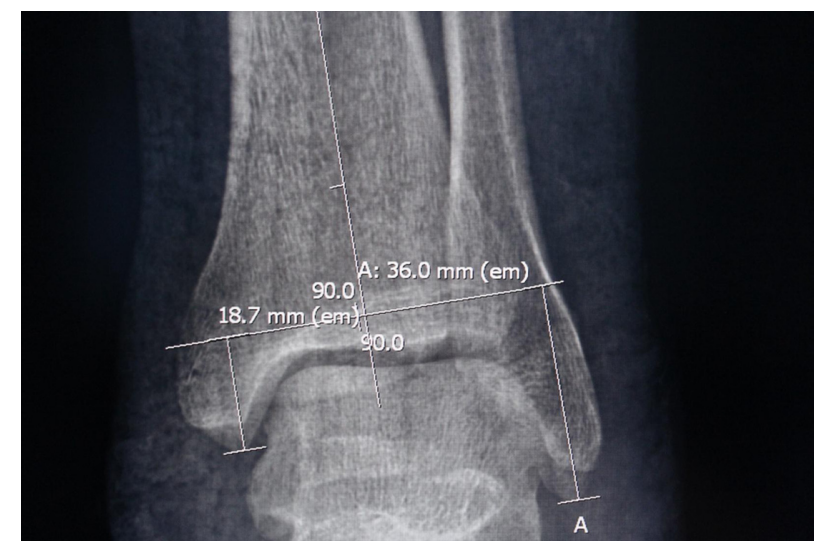

Figure 3 Plain anteroposterior radiograph.

Notes: Plain anteroposterior radiograph shows Elise ratio measured as 0.5 , which suggests a moderate hypoplasia of the medial malleolus. Measurement of Elise ratio on the plain anteroposterior radiograph was made by dividing the medial malleolus length by the lateral malleolus length (normal values fall between 0.58 to 0.62 ). ${ }^{26}$
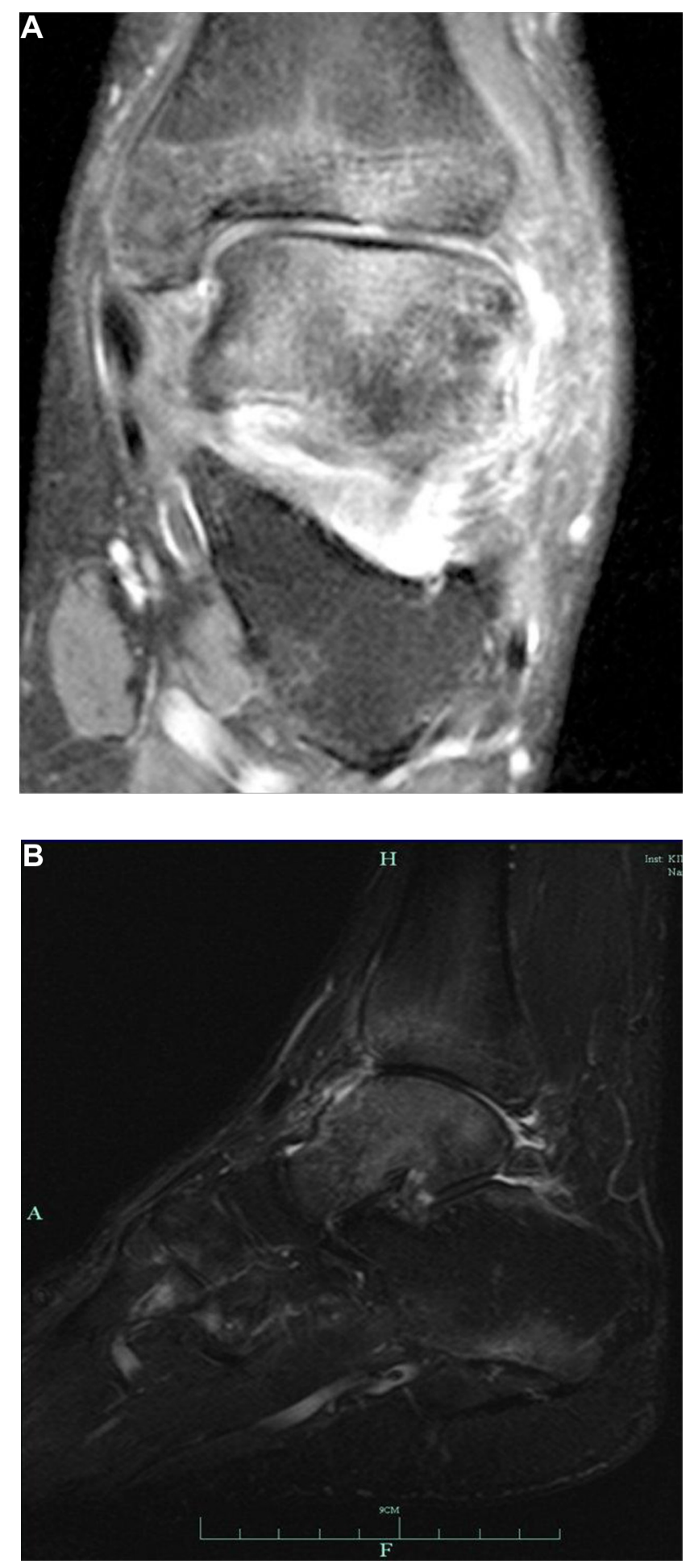

Figure $4 \mathrm{MRI}$ images.

Notes: (A) Coronal proton density fat sat $(31 / 3,640)$ MRI demonstrated bone marrow edema that involved ankle joint articular surface (the mid talar dome) associated with soft tissue swelling in the dorsolateral aspect of the foot. There was also an abnormal increase in signal intensity involving the medial collateral ligament complex; (B) Sagittal T2 fat sat $(7 / / 3,280)$ MRI demonstrated periarticular bone marrow edema, which also involves the tarsometatarsal joints associated with soft tissue hyperemia. This distribution of signal alteration suggests Sudeck's sympathetic dystrophy.

Abbreviation: MRI, magnetic resonance imaging. 

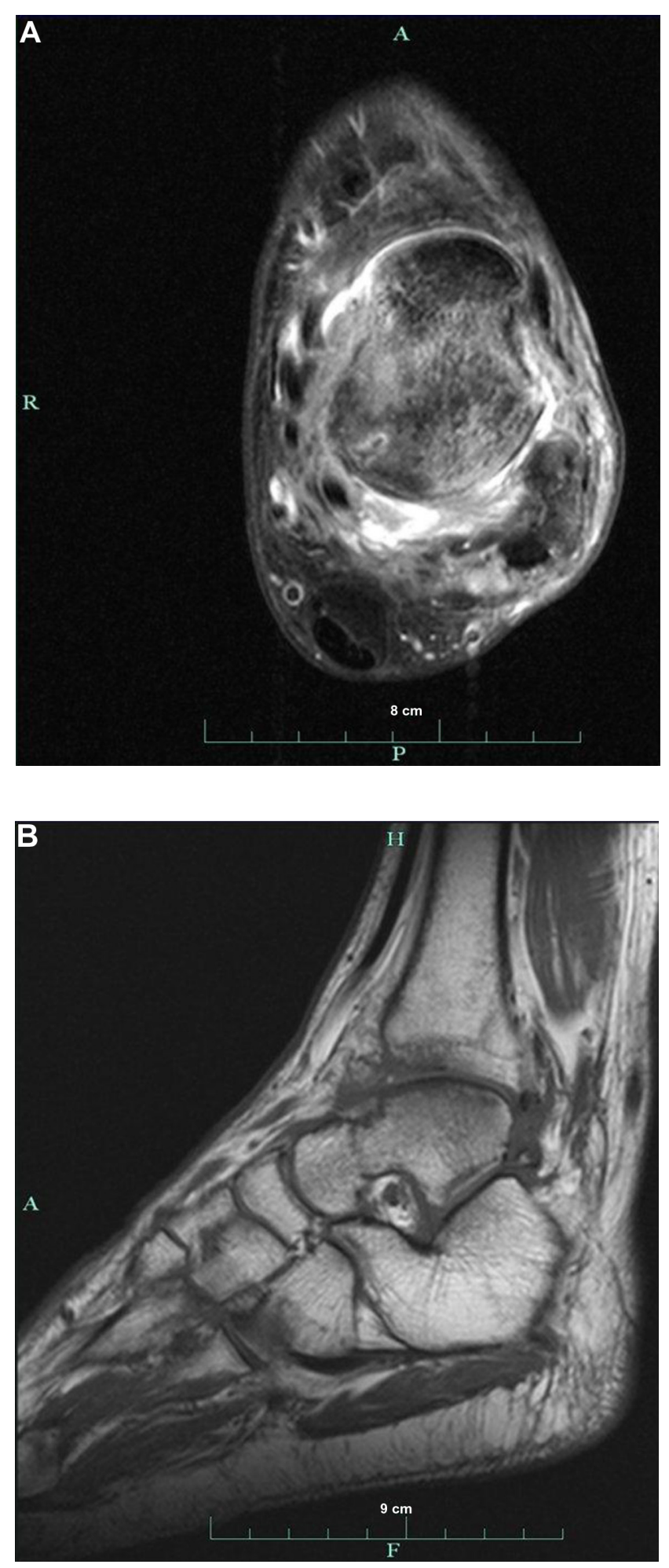

Figure 5 MRI images.

Notes: (A) Axial proton density fat sat (31/3590) MRI demonstrates bone marrow edema with adjacent soft tissue hyperaemia and trace amount of joint effusion; a feature that is not typically seen in avascular necrosis. Note also grade 3 injury to the anterior talofibular ligament as well as the posterior talofibular ligament. (B) Sagittal TI WI (3I/450) MRI demonstrates the preserved appearance of the tarsal canal.

Abbreviation: MRI, magnetic resonance imaging.
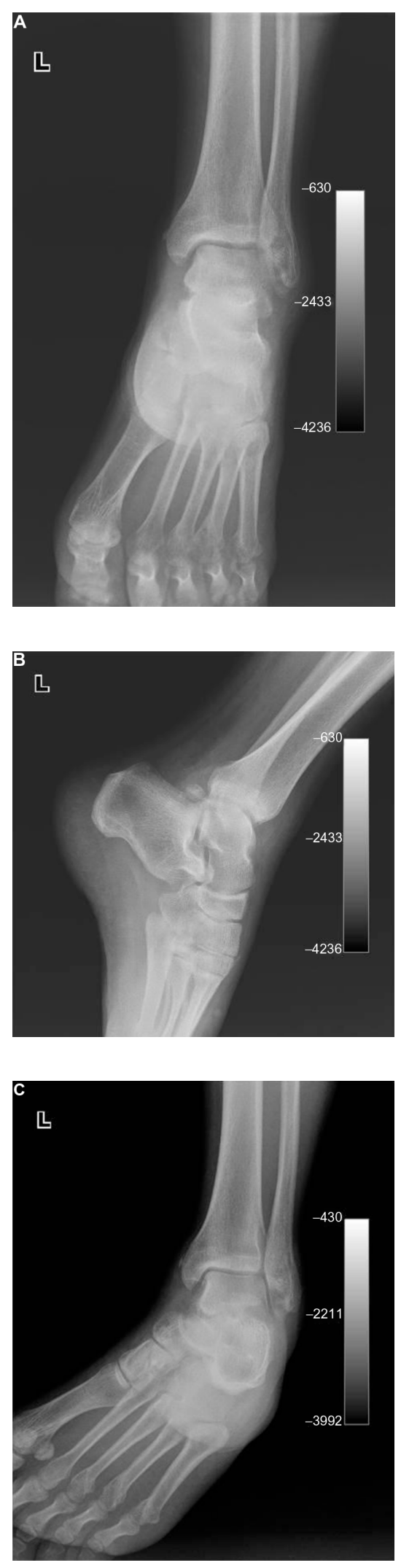

Figure 6 Plain anteroposterior (A), lateral (B), and mortise (C) radiographs of left ankle 6 months postinjury show periarticular reduced bone density along with subchondral talar lucency (Hawkin's sign) especially in the mortise view. 

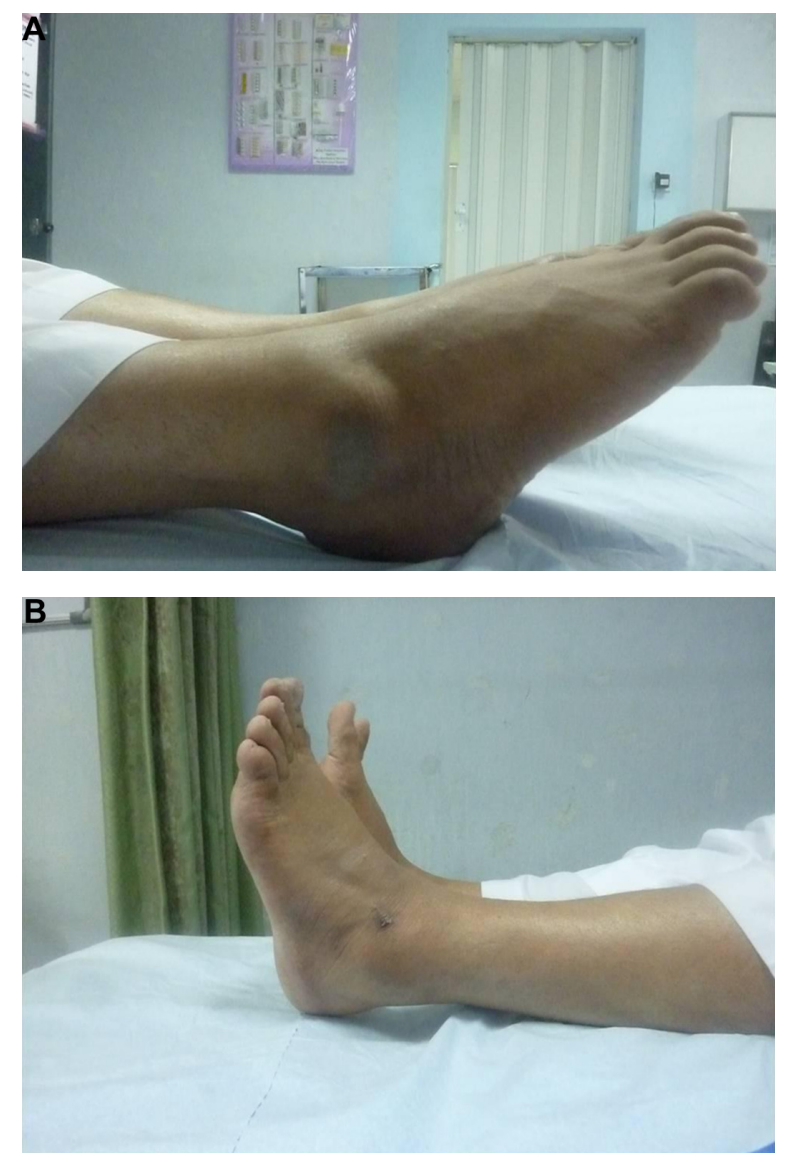

Figure 7 (A and B) Clinical pictures show range of motion of left ankle I year after the injury (some restriction in dorsiflexion) and the site of previous skin pressure.

\section{Technical notes}

- The patient was prepared to be shifted to the operating room as soon as it was possible and it was kept in mind to perform the closed reduction quickly and not to delay anatomic reduction unnecessarily.

- The reduction was done under general anesthesia to achieve good muscle relaxation.

- The knee joint was kept in flexion to relax the Achilles tendon and the posterior leg muscles.

- A longitudinal traction to the heel was applied with the assistant grasping the leg (countertraction).

- The ankle joint was maintained in plantar flexion but the force was not enough to distract the tibiocalcaneal space. Therefore, a calcaneal pin was inserted to maintain longitudinal traction until the engagement of the talus into the tibiocalcaneal space was felt.

- A direct backward and medial pressure to the talus was applied, aiming at reversing the force that caused the injury.

- Once a part of the talus was pushed back to the space, gradual dorsiflexion was carried out.
- The reduction ended with a clunk and restoration of normal alignment.

- Reduction was confirmed by a c-arm machine.

- As a part of preoperative planning, it was anticipated that if the calcaneal pin did not succeed, another pin would be inserted into the tibia to help by using an external fixator or distractor prior to proceeding to open reduction.

\section{Discussion}

The goal of treating any dislocation is prompt anatomic reduction, and talar dislocations are no exception. This can be achieved by closed or open reduction.

Mitchell, ${ }^{24}$ Xarchas et al, ${ }^{18}$ Taymaz and Gunal, ${ }^{19}$ Papanikolaou et al, ${ }^{21}$ El Ibrahimi et al, ${ }^{10}$ Segal and Wasilewski, ${ }^{20}$ Newcomb and Brav,${ }^{27}$ and Kenwright and Taylor $^{8}$ reported successful closed reduction in cases of closed anterolateral TTD under spinal or general anesthesia in which manual longitudinal traction of the foot was done in addition to countertraction of the leg with the knee flexed to relax the Achilles tendon and posterior leg muscles then pushing the talus backward, except for Segal and Wasilewski ${ }^{20}$ who added lateral rotation to the traction and El Ibrahimi et $\mathrm{al}^{10}$ who added plantar flexion. The difficulty in closed reduction that we faced in the present case was reported in many previous studies, ${ }^{11,22,27}$ which is in disagreement with Mitchell ${ }^{24}$ who found that the reduction was easy. Newcomb and $\mathrm{Brav}^{27}$ recommended adding a calcaneal wire and proximal tibial pin to help in the reduction. Kenwright and Taylor ${ }^{8}$ reported successful closed reduction in one case, whereas open reduction was needed in another case due to accompanying talar head fracture and instability necessitating internal fixation. Sharifi et al reported a case of anterolateral TTD with difficult closed reduction even with the use of a calcaneal pin for traction, with the end result being the use of open reduction. They attributed the difficulty in reduction to the irreducibility of the subtalar joint secondary to trapping of the talar neck between flexor tendons. ${ }^{22}$

The most common early complications affecting the prognosis of TTD are AVN and infection. ${ }^{1}$ Infection is more common following open dislocations and is reported only following open reduction of concomitant talar fracture. . $, 5,23^{-}$ To our knowledge, all reported closed anterolateral TTD cases in the literature treated by closed reduction showed no signs of AVN on follow-up and the current case is another example. ${ }^{12,20}$ This preservation of talar viability may be attributed to the partial integrity of ligamentous tissue attached to the talus; thus, a percentage of the blood 
Table I Published case reports of closed anterolateral total talar dislocation, reduction type (closed or open), and the number of cases that developed AVN

\begin{tabular}{|c|c|c|c|c|c|c|c|c|}
\hline Study & $\begin{array}{l}\text { Year of } \\
\text { publication }\end{array}$ & Cases & $\begin{array}{l}\text { Closed } \\
\text { dislocation }\end{array}$ & $\begin{array}{l}\text { Closed } \\
\text { reduction }\end{array}$ & $\begin{array}{l}\text { Open } \\
\text { reduction }\end{array}$ & AVN & Direction & Remarks \\
\hline Mitchell ${ }^{24}$ & 1936 & 1 & I & I & 0 & Unspecified & Anterolateral & \\
\hline $\begin{array}{l}\text { Newcomb } \\
\text { and } \mathrm{Brav}^{27}\end{array}$ & 1948 & I & 1 & I & 0 & 0 & Anterolateral & \\
\hline $\begin{array}{l}\text { Kenwright } \\
\text { and Taylor }\end{array}$ & 1970 & 2 & Unspecified & I & I & 0 & Anterolateral & $\begin{array}{l}\text { Open reduction } \\
\text { because of concomitant } \\
\text { talus fracture }\end{array}$ \\
\hline $\begin{array}{l}\text { Segal and } \\
\text { Wasilewski }{ }^{20}\end{array}$ & 1980 & 1 & 1 & I & 0 & 0 & Anterolateral & \\
\hline Ritsema et $\mathrm{al}^{23}$ & 1988 & 5 & 3 & 0 & 3 & $\begin{array}{l}2 \text { (one medial and } \\
\text { one anterolateral) }\end{array}$ & $\begin{array}{l}2 \text { anterolateral and } \\
2 \text { medial dislocations }\end{array}$ & \\
\hline $\begin{array}{l}\text { Papanikolaou } \\
\text { et } \mathrm{a}^{21}\end{array}$ & 2002 & I & 1 & I & 0 & 0 & Anterolateral & \\
\hline $\begin{array}{l}\text { Taymaz and } \\
\text { Gunal }{ }^{19}\end{array}$ & 2005 & I & 1 & I & 0 & 0 & Anterolateral & \\
\hline Xarchas et al ${ }^{18}$ & 2009 & 2 & 2 & 2 & 0 & $\begin{array}{l}\text { No AVN in one } \\
\text { case, missed f/u } \\
\text { for } 2 \text { nd case }\end{array}$ & & $\begin{array}{l}\text { Good to excellent } \\
\text { results }\end{array}$ \\
\hline Sharifi et $\mathrm{al}^{22}$ & 2009 & I & 1 & 0 & I & 0 & Anterolateral & $\begin{array}{l}\text { Open reduction } \\
\text { because of soft tissue } \\
\text { entrapment }\end{array}$ \\
\hline $\begin{array}{l}\text { El lbrahimi } \\
\text { et al }{ }^{10}\end{array}$ & 2011 & I & 1 & I & 0 & 0 & Anterolateral & \\
\hline Heylen et al"I & 2011 & I & I & 0 & I & 0 & Anterolateral & \\
\hline Our case & 2012 & I & I & I & 0 & 0 & Anterolateral & $\begin{array}{l}\text { Reflex sympathetic } \\
\text { dystrophy }\end{array}$ \\
\hline
\end{tabular}

Abbreviations: AVN, avascular necrosis; f/u, follow-up.

supply remains intact. ${ }^{20,27}$ Whatever blood supply that was disrupted after trauma, all efforts should be directed toward preserving the remaining blood supply, ie, by closed reduction compared to open reduction, which may jeopardize the remaining blood supply. However, the occurrence of AVN might result from the initial injury with marked dislocation, ${ }^{8}$ associated fractures, ${ }^{28}$ or following open reduction. ${ }^{23}$ If AVN appeared following open or closed reduction, it is recommended to avoid early weight-bearing during the course of treatment until the appearance of radiographic signs of revascularization of the talus. ${ }^{1,8,23}$ However, to our knowledge, there are not enough high-level studies to prove the superiority of closed reduction in terms of clinical and radiological outcomes.

The operative technique for closed reduction of closed anterolateral TTD discussed in this paper gathered what was partly described in different reports of similar cases (Table 1). In conclusion, closed reduction has become the preferred way of treatment of closed anterolateral TTD, but there is a need for further higher-level research to prove the superiority of closed over open reduction in such injuries in terms of short- and long-term outcome.

\section{Acknowledgment}

The authors thank Dr Abdullah A Almulhim (Radiology Department at the University of Dammam) who helped in the interpretation of the radiological images.

\section{Disclosure}

The authors report no conflicts of interest in this work.

\section{References}

1. Benjamin J, Nick R, Amit P. Total dislocation of the talus. Eur J Orthop Surg Traumatol. 2011;22(8):633-637.

2. Lee J, Hamilton G. Complete talar extrusion: a case report. J Foot Ankle Surg. 2009;48(3):372-375.

3. Wagner R, Blattert TR, Weckbach A. Talar dislocations. Injury. 2004; 35 Suppl 2:SB36-SB45.

4. Buckingham WW Jr, LeFlore I. Subtalar dislocation of the foot. J Trauma. 1973;13(9):753-765.

5. Detenbeck LC, Kelly PJ. Total dislocation of the talus. J Bone Joint Surg Am. 1969;51-A(2):283-288.

6. Leitner B. The mechanism of total dislocation of the talus. J Bone Joint Surg Am. 1955;37-A(1):89-95.

7. Pinzur MS, Meyer PR Jr. Complete posterior dislocation of the talus. Case report and discussion. Clin Orthop Relat Res. 1978;138:205-209.

8. Kenwright J, Taylor RG. Major injuries of the talus. $J$ Bone Joint Surg Br. 1970;52-B(1):36-48.

9. Mnif H, Zrig M, Koubaa M, Jawahdou R, Hammouda I, Abid A. Reimplantation of a totally extruded talus: a case report. J Foot Ankle Surg. 2010;49(2):172-175. 
10. El Ibrahimi A, Shimi M, Elidrissi M, Daodi A, Elmrini A. A case of closed total dislocation of talus and literature review. Am J Emerg Med. 2011;29(4):475. e1-e3.

11. Heylen S, De Baets T, Verstraete P. Closed total talus dislocation: a case report. Acta Orthop Belg. 2011;77(6):838-842.

12. Schiffer G, Jubel A, Elsner A, Andermahr J. Complete talar dislocation without late osteonecrosis: clinical case and anatomic study. J Foot Ankle Surg. 2007;46(2):120-123.

13. Krasin E, Goldwirth M, Otremski I. Complete open dislocation of the talus. J Accid Emerg Med. 2000;17:53-56.

14. Ely EE, Konstantakos EK, Laughlin RT, Johnson RM, Binski JC. Total dislocation of the talus and the navicular: a case report. J Orthop Trauma. 2009;23(7):546-549.

15. Burston JL, Isenegger $\mathrm{P}$, Zellweger R. Open total talus dislocation: clinical and functional outcomes: a case series. J Trauma. 2011;68(6): 1453-1458.

16. Fleming J, Hurley KK. Total talar extrusion: a case report. J Foot Ankle Surg. 2009;48(6):690. e19-e23.

17. Duncan ST, Wright RD, Lawrence SJ. Pantalar dislocation without extrusion. J Orthopaed Trauma. 2011;1:235378.

18. Xarchas KC, Psillakis IG, Kazakos KJ, Pelekas S, Ververidis AN, Verettas DA. Total dislocation of the talus without a fracture open or closed treatment? report of two cases and review of the literature. Open Orthop J. 2009;3:52-55.
19. Taymaz A, Gunal I. Complete dislocation of the talus unaccompanied by fracture. J Foot Ankle Surg. 2005;44(2):156-158.

20. Segal D, Wasilewski S. Total dislocation of the talus. Case report. J Bone Joint Surg Am. 1980;62(8):1370-1372.

21. Papanikolaou A, Siakantaris P, Maris J, Antoniou N. Successful treatment of total talar dislocation with closed reduction: a case report. Foot Ankle Surg. 2002;8(4):245-248.

22. Sharifi SR, Ebrahimzadeh MH, Ahmadzadeh-Chabok H, KhajehMozaffari J. Closed total talus dislocation without fracture: a case report. Cases J. 2009;2:9132.

23. Ritsema GH. Total talar dislocation. J Trauma. 1988;28(5):692-694.

24. Mitchell JI. Total dislocation of the astragalus. J Bone Joint Surg Am. 1936;18-A:212-214.

25. Palomo-Traver JM, Cruz-Renovell E, Granell-Beltran V, MonzonisGarcia J. Open total talus dislocation: case report and review of the literature. J Orthop Trauma. 1997;11(1):45-49.

26. Elisé S, Maynou C, Mestdagh H, Forgeois P, Labourdette P. [Simple tibiotalar luxation. Apropos of 16 cases]. Acta Orthop Belg. 1998;64(1): 25-34. French.

27. Newcomb WJ, Brav EA. Complete dislocation of the talus. J Bone Joint Surg Am. 1948;30-A:872-874.

28. Penny JN, Davis LA. Fractures and fracture-dislocations of the neck of the talus. J Trauma. 1980;20(12):1029-1037.
Orthopedic Research and Reviews

\section{Publish your work in this journal}

Orthopedic Research and Reviews is an international, peer-reviewed, open access journal focusing on the patho-physiology of the musculoskeletal system, trauma, surgery and other corrective interventions to restore mobility and function. Advances in new technologies, materials, techniques and pharmacological agents are particularly welcome. The journal welcomes

\section{Dovepress}

original research, clinical studies, reviews \& evaluations, expert opinion and commentary, case reports and extended reports. The manuscript management system is completely online and includes a very quick and fair peer-review system, which is all easy to use. Visit http://www.dovepress. com/testimonials.php to read real quotes from published authors. 